Article

\title{
Foreign body ingestion by children: an analysis of age and types at a tertiary hospital in Bangladesh
}

\author{
Tanvir Kabir Chowdhury", Durdana Sadab, Md. Minhajuddin Sajid and Md. Abdullah Al Farooq \\ Department of Pediatric Surgery, Chittagong Medical College Hospital, Chattogram, Bangladesh \\ *Corresponding author: Tanvir Kabir Chowdhury, Department of Pediatric Surgery, Chittagong Medical \\ College Hospital, Chattogram 4203, Bangladesh. Phone: +8801771477766; E-mail: ivan_tanvir@yahoo.com
}

Received: 30 May 2020/Accepted: 24 June 2020/ Published: 30 June 2020

\begin{abstract}
Foreign body (FB) ingestion is common in children worldwide. Type of FB ingestion varies among cultures and countries. We retrospectively reviewed all patients of foreign body ingestion who were admitted in Department of Pediatric Surgery, Chittagong Medical College Hospital from January 2017 to December 2019 (total 3 years). Age, Sex, type of foreign body, hospital stay, management and outcome were analyzed. A total of 91 children were admitted with ingestion of FB during this period; male 61, female 30 (male to female ratio 2:1). Age ranged from 3 months to 12 years (median $3.5 \pm 3.8$ years). Fifty eight percent were less than 5 years old. Children ingested 21 different types of FB; however ingestion of coin was most common (24 patients, $26.37 \%$ ) followed by different types of pins (19 patients, $20.88 \%)$, nail (6 patients, $6.59 \%)$, battery (5 patients, $5.49 \%$ ), screw (5 patients, 5.49\%), needle (4 patients, 4.40\%), ring (4 patients, $4.40 \%$ ) and others (18 patients). Sharp object ingestion is higher in older ( $>5$ year) age group. Hospital stay ranged from 0 day to 19 days (mean $1.6 \pm 2.1$ day). Endoscopic removal needed in 4 patients (coin-2, chain 2), bronchoscopic removal in 1 (pin) and one patient needed laparotomy (open hair pin). There was no mortality. The pattern of FB ingestion is similar to many other countries. Small, smooth objects pass spontaneously. Endoscopic or surgical intervention is sometimes needed if significant symptoms develop or if the object fails to progress through the gastrointestinal tract.
\end{abstract}

Keywords: foreign body; ingestion; children; sharp; blunt; coin

\section{Introduction}

Foreign body (FB) ingestion in children is common and a world-wide problem. Small children tend to put foreign bodies in their mouth due to oral orientation after the age of six months (Yalçin, 2007). Children, especially before 6 years of age, are more susceptible to FB injuries due to the lack of molar teeth, the tendency toward oral exploration, to play while they eat, and the poor coordination of swallowing (Gregori et al., 2010). About $80-90 \%$ of FBs usually pass the gastrointestinal tract uneventfully, 10-20\% require endoscopic removal and $1 \%$ or less require surgery (A-kader, 2010). The type of FB varies between countries depending on their feeding habits and sociocultural characteristics. The European Survey on Foreign Bodies Injuries (ESFBI) study reported that the most common FB were coins, batteries and fish bones (Gregori et al., 2010). Although FB ingestion causes serious problem in less than $1 \%$ of all cases, it causes about 1500 deaths per year in USA. (Chung et al, 2010). Since there is scarcity of reports from Bangladesh, the aim of the study is to report the types of FB ingested, their management and outcome in a tertiary pediatric surgical center in Bangladesh.

\section{Materials and Methods}

2.1. Study design

Hospital based retrospective study.

\subsection{Study Period}

Between January 2017 and December 2019 (3 years). 


\subsection{Place of study}

Department of Pediatric Surgery, Chittagong Medical College Hospital, Bangladesh.

\subsection{Study subjects}

Children aged less than 12 years, diagnosed as FB ingestion after admission in ward were included in the study.

\subsection{Study procedure}

We retrospectively reviewed medical records of 91 patients during the study period. Diagnosis was confirmed by visual observation of FB by the physician or parent during ingestion or after expulsion or extraction of FB and by radiologic findings.

\subsection{Data and variables}

The age and sex, clinical findings, Type of FB, modalities of treatment, hospital stay and outcome of all patients were recorded.

\subsection{Statistical analysis}

Categorical variables were described as frequency and percentage. Continuous variables were expressed as mean or median \pm standard deviation and comparison was done by independent sample t test. All data were expressed as mean \pm standard deviation, whenever possible. Statistical analyses were made through SPSS 22 software by using student $\mathrm{t}$ test. $\mathrm{P}<0.05$ was considered to be significant.

\section{Results}

Among the 91patients, males were $61(67 \%)$ and females were $30(33 \%)$; male to female ratio was 2:1. Age ranged from 3 months to 12 years (median 3.5 \pm 3.8 years). Fifty-three (58\%) children were less than 5 years old, $27(29 \%)$ were between 5-10 years and 11(12\%) patients were more than 10 years old. Figure-1 shows age distribution of patients.

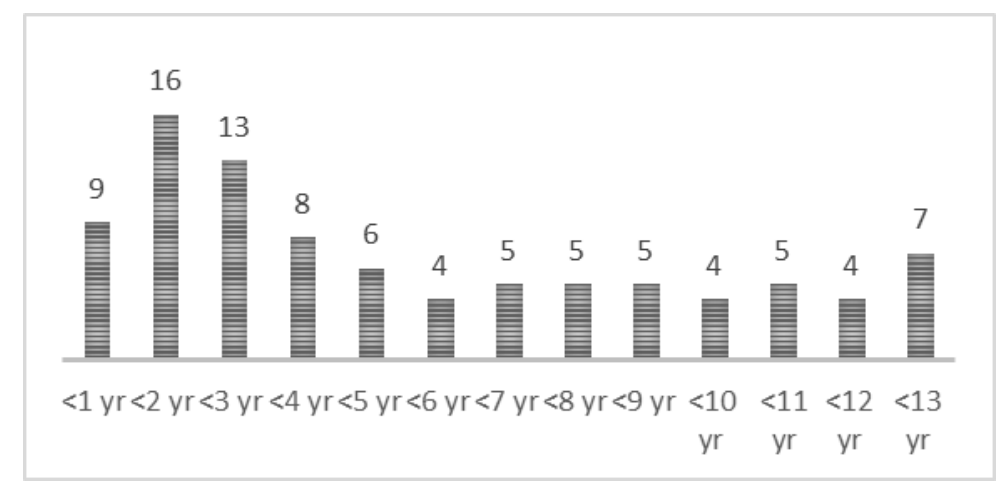

Figure 1. Age distribution of patients.

The children ingested 21 different types of FBs. Majority of the FB were inorganic $83(91.21 \%)$ and only $3(3.3 \%)$ were organic. The rest $5(5.49 \%)$ were unspecified. The most common FB ingested was coin $(24$ patients, 26.37\%). However, 29(31.86\%) patients ingested different types of sharp objects and 21(23.08\%) patients ingested different blunt metallic objects. Table 1 shows different types of FB ingested by the patients.

Table 1. Types of FB ingested.

\begin{tabular}{|llllll|}
\hline Type of FB & No. & \% & Type of FB & No. & \% \\
\hline Coin & 24 & $26.37 \%$ & Key & 2 & $2.20 \%$ \\
Pin & 19 & $20.88 \%$ & Metallic object & 2 & $2.20 \%$ \\
Nail & 6 & $6.59 \%$ & Back of watch & 1 & $1.10 \%$ \\
Battery & 5 & $5.49 \%$ & Clip & 1 & $1.10 \%$ \\
Not specified & 5 & $5.49 \%$ & Cock sheet & 1 & $1.10 \%$ \\
Screw & 5 & $5.49 \%$ & Fish & 1 & $1.10 \%$ \\
Needle & 4 & $4.40 \%$ & Ornament (anklet) & 1 & $1.10 \%$ \\
Ring & 4 & $4.40 \%$ & Plastic dice & 1 & $1.10 \%$ \\
\hline
\end{tabular}


Asian J. Med. Biol. Res. 2020, 6 (2)

\begin{tabular}{|llllll|}
\hline Ear ring & 3 & $3.30 \%$ & Plum seed & 1 & $1.10 \%$ \\
Chain & 2 & $2.20 \%$ & Wood & 1 & $1.10 \%$ \\
Glass & 2 & $2.20 \%$ & & & \\
\hline
\end{tabular}

Diversity of the types of FB ingestion was more in children less than 5 years old (Figure 2). Battery ingestion occurred mainly around infancy (mean age 10 months, range 5 month to 1.5 years) and coin ingestion occurred over a diverse age range of 14 months to 10 years, mean 4.9 years. Ingestion of blunt metallic object ranged from 3 months to 9 years of age, mean 2.49 years and ingestion of sharp metallic object ranged from 1.5 years to 12 years, mean 6.73 years $(\mathrm{P}=0.00)$. Different types of ingested pins were straight pin (12), safety pin (3), hair pin (1), ear pin (1), hijab (veil) pin (2).

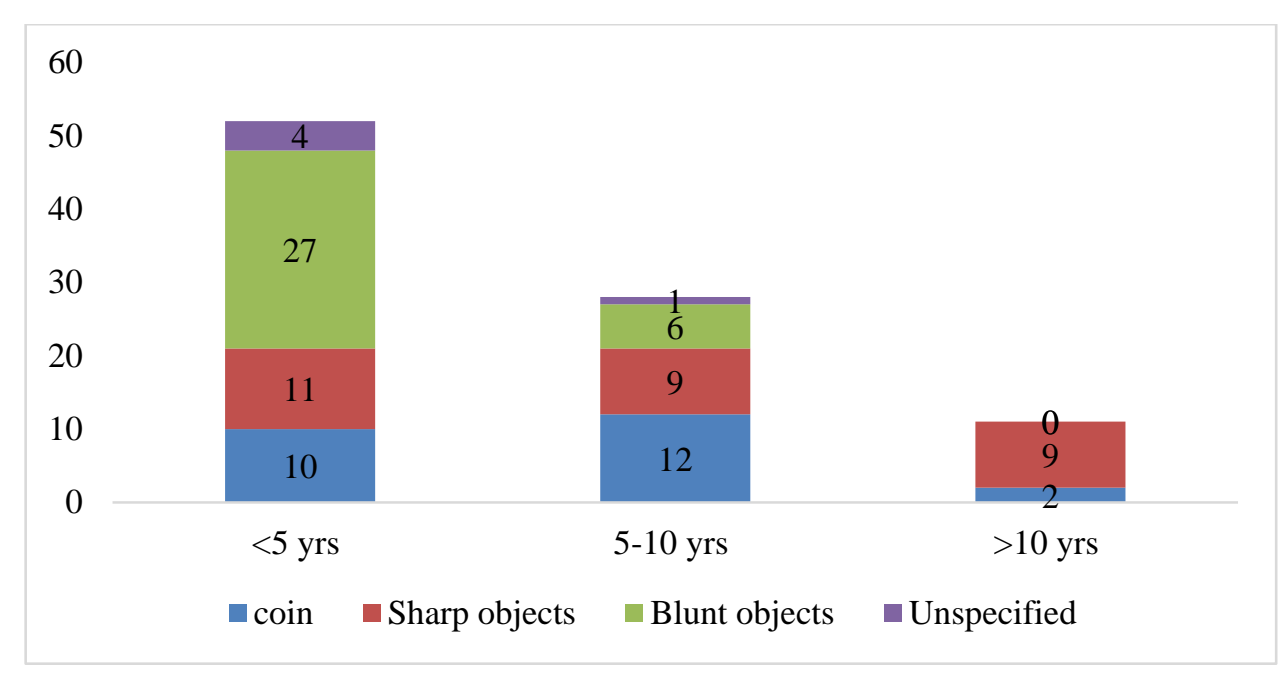

Figure 2. FB ingestion according to age group.

85 patients were treated conservatively and 6 needed intervention. Endoscopic removal needed in 4 patients (coin-2, chain-2), bronchoscopic removal in 1 (pin) and 1 patient needed laparotomy and enterotomy (open hair pin stuck at terminal ileum). Hospital stay ranged from 0 to 19 days, mean $1.6 \pm 2.1$ day. There was no mortality.

\section{Discussion}

FB ingestion represents a severe public health problem in childhood, especially in infants (Passali et al, 2015). During the infancy and early childhood, they evaluate objects by tasting and swallowing those. The exact incidence will never be known because many cases are not brought into medical attention. However, a large number of babies are admitted every year for ingestion of FB and the diagnosis and management are a challenge because of the difficulty in communication and examination. The proportion of cases varies from 6.5 to $80 \%$ and there is a marked ethnic variation between Oriental and Western populations (Pak et al., 2001). Studies from Singapore and Hong Kong reported a 6.5 to $14.32 \%$ incidence, whereas, western studies reported incidences of 50-80\%. It might be due to the fact that FB ingested cases were under reported in oriental countries since a large number of people are not prompt at seeking medical advice in these region (Pak et al., 2001).

The peak incidence of ingestion of FB has been reported to be between 6 months to 3 years (A-kader, 2010). In this study also FB ingestion was higher in less than 5 years age group with a median age of 3.5 years. FB ingestion occurred more in boys than girls in this study which is consistent with most reports. However, one report from USA showed equal male to female distribution. (A-kader, 2010). Conners suggested that older boys ingest FBs due to poor situational decision making (Conners, 2015).

Although, most studies reported that coin is the most commonly ingested FB, some suggested that fish bone ingestion is the most common FB in Asian countries, especially China, where fish is the main diet. Susy Safe database for FB injury showed that among 10,564 cases, 74\% of objects were inorganic and were mostly pearls and balls, followed by coins (Gregori and Foltran, 2012; Passali et al, 2015). However, their report included other routes of entry of FB. Kay and Wyllie suggested that weaning with unfilleted fish into the diet may put the Chinese pediatric population at risk (Kay and Wyllie, 2005). However, Cheng and Tam from China and Hong 
Kong reported that coin ingestion occurred in $49 \%$ patients and fish bone ingestion occurred in $29 \%$ patients (Cheng and Kong, 1999). Although fish is an important part of diet in our riverine country, there were no cases of fish bone ingestion in this study. This is probably due to the fact that impacted fish bones in the esophagus are directly referred to otolaryngology department from the emergency and removed endoscopically there. Some studies from India also reported coin to be the most common type and fish bone ingestion was very infrequent (Nijhawan et al, 2003; Sinha and Kumar, 2016; Lakhwani and Patel, 2018).

Coins that lodge distal to lower esophagus usually pass spontaneously. The most likely site of the coin lodgment is at the upper esophageal sphincter (post-cricoid region, 60-70\%), followed by mid esophagus (at the level of aortic arch,10-20\%) and lower esophagus (just above the lower esophageal sphincter, 20\%) (Kay and Wyllie, 2005). Studies have shown that coins with a diameter between 23.45 and $26 \mathrm{~mm}$ are most likely to be lodged in the esophagus. While most Canadian and American quarters are $24 \mathrm{~mm}$ in diameters; a one take coin in Bangladesh ranges from 16 to $25 \mathrm{~mm}, 2$ taka from 24 to $26.03 \mathrm{~mm}$ and a 5 take coin is $26.8 \mathrm{~mm}$ in diameter (Anonymous, 2020). It is recommended that coins in mid and lower esophagus should be removed by flexible endoscopy and coins in the stomach and intestine do not require intervention (Cheng and Kong, 1999). Coins from upper esophagus can be removed by direct laryngoscopy. Stack and Munter suggested that coins with diameter more than $20 \mathrm{~mm}$ may not pass pylorus and should be removed (Stack and Munter, 1996). Coin ingestion in our series ranged from 1 taka to 5 taka and 2 patients required endoscopic removal from esophagus. However, all other coins passed the esophagus by the time the patients presented. If the coin does not pass spontaneously, timing of repeat $\mathrm{x}$-ray varies from days to weeks among centers and endoscopic removal is performed (Nijhawan et al, 2003; Kay and Wyllie, 2005).

Sharp objects ingestion was also common and varied from straight and curved pin, nail and needle. One needed laparotomy and the other needed bronchoscopic removal from the trachea. Other sharp metals passed spontaneously. According to Jackson's axiom "advancing points perforate and trailing points don't" (Kay and Wyllie, 2005). Straight pins tend to follow it and usually the blunt head passes first with the sharp end trailing. Once they are in intestine, they usually traverse the rest of gastrointestinal tract safely (Cheng and Kong, 1999). However, ingestion of large number of straight pins increases the risk of perforation (Aktay and Werlin, 2002; Kay and Wyllie, 2005). Non straight pins might cause perforation and majority of perforations occur near the ileocecal valve. Safety pin ingestions are common since it is used commonly in young children's and their mother's clothing. However, its incidence has decreased in USA due to modification of diapers. We only had 2 cases of safety pin ingestion. Safety pin frequently lodges in the esophagus, stomach or duodenal loop. Although closed pins are safely removed, open pins might cause perforation or injury to the gut wall. For safe endoscopic removal of sharp object, different methods are used such as over-tube, latex hood and friction fit adaptor (Chaves et al., 1972; Wahbeh et al., 2002; Kay and Wyllie, 2005).

Toy and toy part ingestion were reported previously, however, due to safety of making toys it is less reported now a days. We did not have any case of toy part ingestion. However, battery ingestion occurred in 5 cases. Battery ingestion should be monitored closely since it may cause injury due to presence of caustic material in it and perhaps due to discharge of current (Wahbeh et al., 2002). However, if the battery is in the stomach and if there is no symptom, the patient can be observed. Wyllie and Key suggested that if the battery is more than 15 $\mathrm{mm}$ in size and does not pass the duodenum within 48 hours, it should be removed endoscopically (Wahbeh $e t$ al., 2002). An AA battery $(12 \mathrm{~mm} \times 5 \mathrm{~cm})$ would be unlikely to pass in a 1-year-old child. Symptomatic patients with gastric batteries of any size should be considered for early removal.

The majority of FBs that reach the stomach, usually pass uneventfully through the remainder of the gastrointestinal tract within 4 to 6 days. In fewer than $10 \%$ of cases, foreign bodies may be impacted in the intestines. In a systematic review, 5 studies reported that FB most commonly impacted in the esophagus and 4 studies found the stomach as the most common site (Jayachandra and Eslick, 2013). The other sites of impaction were pylorus, duodenum and ileocecal valve. Objects greater than $10 \mathrm{~cm}$ in length cannot pass through the duodenal $\mathrm{C}$ loop and should be removed endoscopically as soon as possible. A combination of length and caliber may prevent FB to pass spontaneously. An ovoid object greater than $5 \mathrm{~cm}$ usually do not pass spontaneously (Wahbeh et al., 2002).

Management of FB ingestion varies from center to center and is based on clinical experience mainly since there is lack of controlled studies. It is usually decided on individual basis depending on type, location, size of the FB and the patient, presence of symptoms, and time since ingestion. The challenge to the physician is to avoid over testing and unnecessary intervention while recognizing the high-risk patient who will need intervention. While the overall complication rate is about $1 \%$, about $15-35 \%$ of sharp instrument can cause complications such as perforation and lacerations. A variety of methods have been described in the literature for removal of FBs such as rigid and flexible esophagoscopy, McGill's forceps, Foley catheter extraction, esophageal bougienage and 
use of magnetic probe (Wahbeh, Wyllie and Kay, 2002; Jayachandra and Eslick, 2013). Many a times, ingestion of FB is not noticed by parents and the symptoms may be misinterpreted as a gastrointestinal or respiratory infection which may cause delays in diagnosis, thereby increasing the risk of complications (Passali et al., 2015).

Distracted or incorrect adult supervision is commonly a cause of FB ingestion in children. Gregori reported that a parent or care giver was present in $49 \%$ cases of FB ingestion and the child was eating in $34 \%$ and playing in 59\% of cases (Gregori, 2006; Gregori D, 2008). The 2010 American Academy of Pediatrics Policy Statement on the Prevention of Choking Among Children suggested that the ideal management of foreign body ingestion is preventive. Attention to toy safety, guidance on prevention and safety to parents by pediatricians during every well child visit and use of the visit to emergency department during a FB ingestion as a "teachable moment" regarding appropriate toys and foods are important suggestions (Baum et al., 2010). The Susy safe project suggested that informative campaign should be carried out to emphasize families when a young child is manipulating objects (Gregori, 2006; Gregori, 2008). Most FBs are not the items for playing or other use by the children and can be kept out of reach of the child. If the parent or caregiver has knowledge about the most common types of FBs ingested by babies, many incidences can be avoided.

\section{Conclusions}

Children ingest a variety of FB. Most are passed spontaneously but sometimes it may have serious consequences and require intervention or surgery based on the type and location of FB. Parents or care givers need to be more concentrating towards babies and keeping object out of the reach of their child.

\section{Conflict of interest}

None to declare.

\section{References}

Anonymous, 2020. Search the coin catalogue. In Numista web page. URL: https://en.numista.com/catalogue/index.php? $\mathrm{r}=1+$ taka\&ct=coin $\& \mathrm{p}=1 \& \mathrm{x}=0 \& \mathrm{y}=0$. Accessed 28.05.2020

A-kader HH, 2010. Foreign body ingestion: children like to put objects in their mouth. World J. Pediatr., 6: 301310.

Aktay AN and SL Werlin, 2002. Case report penetration of the stomach by an accidentally ingested straight pin. J. Pediatr. Gastroenterol. Nutr., 34: 81-82.

Baum C, D Durbin and R Lichenstein, 2010. Policy statement-prevention of choking among children. Pediatrics, 125: 601-607.

Chaves DM, S Ishioka and P Sakai, 1972. Removal of a foreign body from the upper gastrointestinal tract with a flexible endoscope: a prospective study. Endoscopy, 36: 887-892. Cheng BW and H Kong, 1999. Foreignbody ingestion in children: experience with 1,265 cases. J. Pediatr. Surg., 34: 1472-1476.

Conners GP, 2015. Managing pediatric foreign body ingestions. Missouri Medicine, 112: 181-186.

Gregori D, 2006. The Susy Safe Project. A web-based registry of foreign bodies injuries in children. Int. J. Pediatr. Otorhinolaryngol., 70:1663-1664.

Gregori D, 2008. Preventing foreign body injuries in children: a key role to play for the injury community. Injury Prevention, 14: 411.

Gregori D, C Scarinzi, B Morra, L Salerni, P Berchialla, S Snidero, R Corradetti, D Passali and ESFBI Study Group, 2010. Ingested foreign bodies causing complications and requiring hospitalization in European children: Results from the ESFBI study. Pediatr. Int., 52: 26-32.

Gregori D and F Foltran, 2012. The Susy Safe Project overview after the first four years of activity. Int. J. Pediatr. Otorhinolaryngol., 76S: S3-S11.

Jayachandra S and GD Eslick, 2013. A systematic review of paediatric foreign body ingestion: presentation, complications, and management. Int. J. Pediatr. Otorhinolaryngol., 77: 311-317.

Kay M and R Wyllie, 2005. Pediatric foreign bodies and their management. Curr. Gastroenterol. Rep., 7: 212218.

Lakhwani S and B Patel, 2018. Foreign body injection in children: clinical feature, management and outcome study in western India. Indian J. Basic Appl. Med. Res., 7: 548-553.

Nijhawan S, L Shimpi, A Mathur and VRR Mathur, 2003. Management of ingested foreign bodies in upper gastrointestinal tract: report on 170 patients. Ind. J. Gastr., 22: 46-48.

Pak MW, WC Lee, HK Fung and CA van Hasselt, 2001. A prospective study of foreign-body ingestion in 311 children. Int. J. Pediatr. Otorhinolaryngol., 58: 37-45. 
Passali D, D Gregori, G Lorenzoni, M Cocca and FM Passali, 2015. Foreign body injuries in children: a review. Acta Otorhinolaryngol. Ital., 35: 265-271.

Sinha S and S Kumar, 2016. Upper gastrointestinal tract foreign body in children India. Int. Surg. J., 3: 20462049.

Stack LB and DW Munter, 1996. Foreign bodies in the gastrointestinal tract. Emerg. Med. Clin. North Am., 14: 493-521.

Yalçin S, I Karnak, AO Ciftei, ME Senocak, FC Tanyel and N Buyukpamukcu, 2007. Foreign body ingestion in children: an analysis of pediatric surgical practice. Pediatr. Surg. Int., 23: 755-76.

Wahbeh G, R Wyllie and M Kay, 2002. Foreign body ingestion in infants and children: location, location, location. Clin Pediatr., 41: 633-640. 